\title{
DÜŞEY MADEN KUYULARINDA BETON TAHKIMMAT KALINLIKLARININ BELİRLENMESİNE YÖNELİK BİR TASARIM YAKLAŞIMI
}

\author{
1Said Shahzada HUSSAINI, 2ỉhsan ÖZKAN \\ 1,2Selçuk Üniversitesi, Mühendislik Fakültesi, Maden Mühendisliği Bölümü, Kampüs, Konya \\ 1seh.afg20@gmail.com, 20zkani@selcuk.edu.tr
}

(Geliş/Received: 03.07.2017; Kabul/Accepted in Revised Form: 17.07.2017)

ÖZ: Yeraltı maden ocaklarında kuyu duraylılığı çok önemlidir. Kuyu cidarında yapılacak olan tahkimat bunu sağlayabilmektedir. Bu çalışmada, $9 \mathrm{~m}$ çaplı ve $900 \mathrm{~m}$ derinliğe ulaşan düşey bir kuyunun beton tahkimat kalınlıkları, iki boyutlu sayısal analizler ile belirlenmiştir. Sayısal analizlerde farklı derinlik $(Z)$, tek eksenli basma dayanımı $\left(\sigma_{\mathrm{ci}}\right)$, kaya kütle sınıflama sistemi (M-RMR), kuyu kazısında patlatmaya dayalı çevre kayacın örselenme durumu (D) parametreleri kullanılmıştır. $9 \mathrm{~m}$ çaplı kuyunun sırasıyla 100, 300, 500, 700 ve 900 metrelerinin her birinde M-RMR değerinin 10, 20, 30, 40, 50, 60, 70, 80, 90, 100 olduğu durumlarda ve tek eksenli basma dayanımının 50MPa koşulu altında ve ayrica patlatmaya dayalı kuyu çevre kayaçlarında oluşan örselenme $(D=0$ ve $D=0.5)$ durumuna bağlı sayısal analizler Phase2 yazılımı ile yapılmıştır. Sonuç olarak parametrik bu çalışmada, toplam 100 senaryo analiz edilmiştir. Her bir senaryo için C20 sınıfı beton ile optimum beton tahkimat kalınlıkları ( $\left.t_{c}\right)$ belirlenmiştir. Phase2 yazılımından sırasıyla, en büyük asal gerilme $\left(\sigma_{1}\right)$, toplam yerdeğiştirme $(U)$, kuyu çevre kayacında oluşan yenilen element sayısı, dayanım faktörü (SF) ve yenilme bölgesi kalınlığı $\left(h_{t}\right)$ belirlenmiştir. Oluşturulan veri tabanı yardımıyla beton tahkimat tasarımı için bütünleyici 10 abak hazırlanmıştır. Kaya kütle sınıflama değerinin (M-RMR) bilinmesi durumunda; geliştirilen ilgili abak kullanılarak kuyu çevre kayacında yenilme bölgesi kalınlığ $\left(h_{t}\right)$, beton tahkimat kalınlığı $\left(t_{c}\right)$ ve bu beton tahkimatın uygulanması sonucunda kuyu cidarında oluşacak yerdeğiştirme miktarı (U) belirlenebilmektedir.

Anahtar Kelimeler: Beton tahkimat, Maden kuyusu,Sayısal çözümlemeler

\section{A Design Approach for Determination of Concrete Support Thickness in Vertical Mine Shafts}

ABSTRACT: Stability in underground shafts is very important. Shaft lining can supply it. In this study, the concrete support thicknesses of a vertical shaft of $9 \mathrm{~m}$ diameter and reaching a depth of $900 \mathrm{~m}$ were determined by 2D numerical analysis. In numerical analysis different depths (Z), uniaxial compressive strength $\left(\sigma_{\mathrm{ci}}\right)$, rock mass classification system $(\mathrm{M}-\mathrm{RMR})$ and also the surrounding rocks situation based on blasting (D) parameters were used. In each of the nine-meter-diameter shafts has 100, 300, 500, 700 and 900 meters where the M-RMR value is 10, 20, 30, 40, 50, 60, 70, 80, 90, 100 and the uniaxial compressive strength $50 \mathrm{MPa}$ and also situation formed in shafts surrounding rocks based on blasting (D $=0$ and $\mathrm{D}=0.5)$ the numerical analysis were made by Phase 2 software. As a result, in this parametric study, a total of 100 scenarios were analysis. The optimum thickness ( $\left.t_{c}\right)$ of concrete support with C20 class concrete have been identified for each scenario. The maximum principal stresses $\left(\sigma_{1}\right)$, total displacement (U), the number of yielded elements formed in the surrounding rocks, strength factor (SF) and thickness of yielded region $\left(h_{t}\right)$ respectively were determined. Using Phase2 software 10 integrated charts were prepared. By data base to determine of concrete support thickness If the rock mass classification value (M-RMR) is known the thickness of yielded surrounding rocks $\left(\mathrm{h}_{\mathrm{t}}\right)$, concrete support thickness $\left(t_{c}\right)$ the total of displacement $(U)$ to be formed in the shaft can be determined.

Key Words: Concrete support, Mine shaft, Numerical analysis 


\section{GİRİŞ (INTRODUCTION)}

Yeraltı madencilik çalışmalarında düşey kuyuların ana görevleri; yeraltı çalışmaları için gerekli temiz havanın, tahkimat malzemelerinin, basınçlı havanın, haberleşme ve aydınlatma amaçlı iletim hatlarının yeraltına iletilmesinde ve ayrıca yeraltından üretilen cevherin yeryüzüne nakliyesinde bir yol görevi görmektir. Kuyu açma, büyük hazırlıkların önemli bir kısmını oluşturmaktadır. Kuyu, istenilen derinliğe ulaştıktan sonra kuyudan itibaren diğer hazırlıklara başlanır. Kuyunun açıldığı kayaç sağlam ve az su gelirine sahipse normal kuyu açma yöntemleri uygulanır. Buna karşı kayaç sağlam değil ve fazla su gelirine sahipse veya bu iki husus birlikte etki ediyorsa özel kuyu açma yöntemlerinin uygulanışı zorunlu hale gelmektedir (Saltoğlu, 1976). Kuyu kesitleri kare, dikdörtgen, daire ve elips olarak sıralanabilir. Kuyunun birinci işlevi olan nakliye ele alınırsa en uygun kesit kare ve dikdörtgen kesit olmaktadır. Ancak duraylılık açısından bakılırsa yeraltı arazi gerilmelerinin en uygun dağılım gösterdiği kesitin daire kesit olduğu bilinmektedir. Bu nedenle sı ̆ derinliklerde kare ve dikdörtgen kesit tercih edilirken derinliğin arttığı madenlerde genelde daire kesit tercih edilmektedir. Maden kuyu kazısında tahkimat tasarım çalı̧malarında kaya kütle özellikleri, derinliğe bağlı arazi gerilmeleri ve beton tahkimat özellikleri öncelikle önem kazanmaktadır.

\section{KAYA KÜTLE SINIFLAMA SİSTEMLERİ (ROCK MASS CLASSIFICATION SYSTEMS)}

Kaya mühendislik yapılarının tahkimat tasarım çalışmalarında ihtiyaç duyulan girdi parametrelerinin belirlenmesinde kaya kütle sınıflama çalışmaları sıklıkla kullanılmaktadır. Tasarım çalışmalarında genel olarak RMR (Bieniawski, 1973; Bieniawski, 1989) ve Q (Barton ve diğ., 1974) sınıflama sistemleri yaygın olarak kullanılmaktadır. Günümüzde 30`a yakın geliştirilmiş olan sınıflama sistemi mevcuttur. Bunların büyük bir çoğunluğu RMR (Rock Mass Rating - Jeomekanik Sınıflama Sistemi) ve Q (Rock Mass Quality - Kaya Kalite İndeksi) sınıflama sistemlerinin özel kaya yapıları için yeniden düzenlenmesi ile ortaya çıkmıştır. Özellikle zayıf-tabakalı-kil içerikli anizotropik ve kırıklı kaya kütlelerinde, RMR ve Q sinıflama sistemlerine ait bazı kütle parametrelerinin belirlenmesinde yetersiz kaldığını belirleyen Unal ve Ozkan (1990), M-RMR (Modified Rock Mass Rating-Yeniden Düzenlenen Kaya Kütle indeksi) sınıflama sistemini geliştirmişlerdir.

Sınıflama sisteminin uygulanması için öncelikle, kaya kütlesi belirli özellikleri açısından benzerlik taşıyan yapısal bölgelere ayrılır. Pek çok durumda yapısal bölgelerin sınırları; fay ve dayk gibi ana süreksizliklerle çakışmaktadır. Yapısal bölgeler belirlendikten sonra, kazı aynaları boyunca veya sondaj karotları üzerinde sınıflandırmanın gerektirdiği parametreler tayin edilir. RMR ile ilgili parametreler kullanılarak "Temel, Düzeltilmiş ve Tasarım RMR indeks değerleri" belirlenebilmektedir. RMR sınıflama indeks değeri 0-100 arasında değişmektedir (Bieniawski, 1989).

Unal ve Ozkan (2012), 1989-2005 yılları arasında ülkemizde ETIBBANK-Bigadiç-Simav kolemanit, TKİ-OAL-Çayırhan kömür, Çayeli Bakır İşletmesi-ÇBİ bakır ve ETİBANK-Beypazarı-Trona maden ocaklarında karşılaşılaşılan kaya kütlesinin RMR (Bieniawski, 1973; Bieniawski, 1989) ve Q (Barton ve diğ., 1974) sınıflandırma indeks değerlerini belirlenmeye çalışmışlardır. Bu çalışmalarında araştırmacılar, özellikle zayıf, anizotropik, tabakalı, kil içerikli ve çatlaklı kaya bölgelerinde kütle parametrelerinin belirlenmesinde RMR ve $Q$ sistemlerinin yetersiz kaldığını tespit etmişlerdir. Zayıf, anizotropik, tabakalı, kil içerikli, çatlaklı kaya yapıları için geliştirilen M-RMR sistemine (Unal ve Ozkan, 1990) ait değerlendirmeler araştırmacılar tarafından çeşitli yurt içi ve yurt dışı yayınlarda (Unal ve Ozkan, 1988; Ozkan, 1989; Unal ve Ozkan, 1990; Ulusay ve diğ., 1992; Unal ve diğ., 1992; Ozkan, 1995; Ozkan ve Unal, 1996; Unal, 1996; Ozkan ve Unal, 2012) ayrıntıları ile sunulmuştur. Bu çalışmada dikkate alınan M-RMR sınıflama sistemi için Unal ve Ozkan (1990) tarafından önerilen eşitlik aslında üç parçadan oluşmaktadır. Bunlar sırasıyla Temel M-RMR, Düzeltilmiş M-RMR ve Tasarım M-RMR olarak adlandırılabilir (Unal ve Ozkan, 1990). Bahsedilen eşitlikler aşağıda sunulmuştur. 
Temel M-RMR $=$ Fc $\left\{[\right.$ IPLT] $\left.]+\left[\operatorname{IRQD}_{\mathrm{R}}\right]+[\mathrm{IJ} \mathrm{J}]\right\}+[\mathrm{IJS}]+[\mathrm{IGW}]$

Düzeltilmiş M-RMR $=[$ Temel M-RMR $]+[$ Ior $]$

Tasarım M-RMR= [Düzeltilmiş M-RMR $]^{*}\left[\mathrm{~A}_{w}{ }^{*} \mathrm{Ab}_{b}\right]$

Eşitlik 1-3'de geçen parametreler sırasıyla;

I $\sigma_{c} \quad$ : Tek eksenli basınç dayanımına bağlı indeks değeri (0-15)

IpLt : Nokta yükleme dayanımına bağlı indeks değeri (0-15)

IRQD $\quad$ : RQD (Rock Quality Designation- Kaya Kalite Değeri) değerine bağlı indeks değeri (0-20)

Ijs : Süreksizlikler arası mesafeye bağlı indeks değeri (0-20)

IJc : Süreksizlikler arası durum indeks değeri (0-30)

IGw : Yeraltı su durumuna bağlı indeks değeri (0-15)

Ior : Eklem takım konumuna bağlı indeks değeri (maden galeri ve tüneller için : 0-(-12))

$F_{c} \quad$ : Suda dağılma dayanımına bağlı bir katsayı (0.7-1.15)

Aw : Büyük süreksizlik düzlemi ve zayıflık düzlemlerine dayalı düzeltme katsayısı (0.70-1.0)

$\mathrm{Ab} \quad$ : Patlatmaya dayalı düzeltme katsayısı (0.80-1.0)

\section{MADEN KUYULARI IÇİN BETON TAHKIMAT TASARIM YAKLAŞIMLARI (CONCRETE SUPPORT DESIGN APPROACHES FOR MINE SHAFTS)}

Dairesel maden kuyularının tahkimat çalışmalarında tahkimat elemanı olarak beton tahkimat sıklıkla kullanılmaktadır. Elastik teoriye göre geliştirilen beton tahkimat yönelik eşitlikler aşağıda sunulmuştur (Carranza-Torres ve Fairhurst, 2000).

$$
\begin{aligned}
& \mathrm{P}_{\mathrm{s}}^{\max }=\frac{\sigma_{c c}}{2}\left[\frac{\left(r-t_{c}\right)^{2}}{r^{2}}\right] \\
& t_{c}=r\left[1-\sqrt{1-\frac{2 P_{s}^{\max }}{\sigma_{c c}}}\right] \\
& K_{s}=\frac{E_{c}}{\left(1-v_{c}\right) r} \frac{r^{2}-\left(r-t_{c}\right)^{2}}{\left(1-2 v_{c}\right) r^{2}+\left(r-t_{c}\right)^{2}}
\end{aligned}
$$

Burada:

$\mathrm{P}_{\mathrm{s}}^{\max } \quad$ : Beton tahkimatın yenilmeden önce taşıyabileceği en yüksek basınç gerilmesi(MPa)

$\sigma_{c c} \quad$ : Beton malzemesinin tek eksenli basma dayanımı (MPa)

$\mathrm{r} \quad$ : Düşey kuyu yarıçapı $(\mathrm{m})$

$t_{c} \quad$ : Beton tahkimat kalınlığ $(\mathrm{m})$

$\mathrm{E}_{\mathrm{c}} \quad$ : Beton malzemesinin Elastik Modülü $(\mathrm{MPa})$

$\nu_{c} \quad$ : Poisson oranı

$\mathrm{K}_{\mathrm{s}} \quad$ : Beton malzemesinin elastik katılı̆̆ $(\mathrm{MPa} / \mathrm{m})$

\section{SAYISAL ANALİZLER İÇİN GİRDİ PARAMETRELERİ (INPUT PARAMETERS FOR NUMERICAL ANALYSIS)}

Bu çalışmada dairesel kesitli maden kuyusunun kumtaşı içerisinde açıldığı kabul edilmiştir. Kuyu çapı (2r) 9 m ve derinliği (Z) $900 \mathrm{~m}$ seçilmiştir. Bu çerçevede RocLab (Rocscience, 2002) programı kullanılarak kumtaşı kaya birimi için aşağıda sıralanan iki temel parametre tespit edilmiştir.

1. Genelleştirilmiş Hoek-Brown görgül yenilme ölçütünde (Hoek ve ark., 1995) kullanılan sağlam kaya sabiti $\left(\mathrm{m}_{\mathrm{i}}\right)$ değerinin kumtaşı kaya birimi için 10 olduğu tespit edilmiştir.

2. Kumtaşı kaya birimine ait modül oranı (MR) değerinin 200 olduğu tespit edilmiştir. 
Sayısal çözümlemelerde kullanılacak girdi parametrelerinin hazırlanmasında temel olarak derinlik $(\mathrm{Z}, \mathrm{m})$, kaya malzemesinin tek eksenli basma dayanımı $\left(\sigma_{\mathrm{c} i}, \mathrm{MPa}\right)$, kaya kütle sınıflama sistemi $(\mathrm{M}-\mathrm{RMR})$ ve kuyu açılırken örselenme durumunu gösteren sabit (D) dikkate alınmıştır. Bu değerlere ait aralıklar aşağ1da verilmiştir.

1. Derinlik (Z) parametresi $100 \mathrm{~m}, 300 \mathrm{~m}, 500 \mathrm{~m}, 700 \mathrm{~m}$ ve $900 \mathrm{~m}$ olarak dikkate alınmıştır.

2. Kaya malzemesinin tek eksenli basma dayanımı $\left(\sigma_{\mathrm{c} i}, \mathrm{MPa}\right)$ parametresi $50 \mathrm{MPa}$ olarak her derinlik (Z) için ayrı ayrı dikkate alınmıştır.

3. Kaya kütle sinıflama sistemi (M-RMR) parametresi 10, 20, 30, 40, 50, 60, 70, 80, 90 ve 100 değerleri her derinlik (Z) için ayrı ayrı dikkate alınmıştır.

4. Kuyu açllırken örselenme durumunu gösteren sabit (D) için örselenmemiş koşuluna ait $\mathrm{D}=0$ değeri dikkate alınırken örselenmiş durum için $\mathrm{D}=0.5$ hesaplamalara dahil edilmiştir.

Yukarıda özetlenen ana parametrelere ait girdi verilerinin tespiti için RocLab (Rocscience, 2002) programı kullanılarak elde edilen sonuçlar sırasıyla aşağıda verilmiştir (Çizelge 1).

İki boyutlu düzlemde sayısal analiz yapabilen Phase2 (Rocscience, 2002) yazılımı için hazırlanan modelde kullanmak amacıyla seçilen beton tahkimata ait mekanik özellikler topluca Çizelge 2'de sunulmuştur. $\mathrm{Bu}$ çalışmada $\mathrm{C} 20$ beton sınıfı $\left(\sigma_{\mathrm{cc}}=20 \mathrm{MPa}\right)$ için başlangıçta rastgele seçilen beton kalınlığı her bir analiz koşulunda sistematik olarak değiştirilmiş ve optimum beton kalınlıkları $\left(t_{c}\right)$ tespit edilmiş ve böylelikle tahkimata etkiyen $\mathrm{P}_{0}(\mathrm{MPa})$ basınç değerleri Phase2 yardımıyla belirlenmiştir. Sayısal analizlerde kullanılan kaya kütle malzemesi ve beton tahkimat plastik ortam kabul edilmiş ve genelleştirilmiş Hoek-Brown yenilme ölçütü kullanılmıştır.

Çizelge 1. Patlatma ile kazı çalışmalarında örselenmemiş $(D=0)$ ve örselenmiş $(D=0.5)$ koşulu altında kuyu çevre kayacına ait girdi parametre aralığ1

Table 1. Input parameter ranges for undisturbed $(D=0)$ and disturbed $(D=0.5)$ shaft environment rock in excavation

\begin{tabular}{|c|c|c|}
\hline Girdi parametreler & $\begin{array}{c}\sigma_{\mathrm{ci}}=50 \mathrm{MPa} \\
\mathrm{D}=0 \text { (örselenmemiş durum) }\end{array}$ & $\begin{array}{c}\sigma_{\mathrm{ci}}=50 \mathrm{MPa} \\
\mathrm{D}=\mathbf{0 . 5} \text { (örselenmiş durum) }\end{array}$ \\
\hline M-RMR & $10-100$ & $10-100$ \\
\hline Derinlik (m) & $100-900$ & $100-900$ \\
\hline MR & 200 & 200 \\
\hline $\mathbf{m}_{\mathrm{i}}$ & 10 & 10 \\
\hline $\mathbf{m b}$ & $0.402-10$ & $0.138-10$ \\
\hline$S$ & $0.0000454-1$ & $0.0000614-1$ \\
\hline A & 0.5-0.585 & $0.5-0.585$ \\
\hline c (MPa) & $0.48-5.042$ & $0.48-5$ \\
\hline$\varphi\left(^{\circ}\right)$ & $17.98-42.95$ & $11.1-42.95$ \\
\hline$\sigma_{t}(\mathrm{MPa})$ & $(-0.003)-(-2.5)$ & $(-0.002)-(-5)$ \\
\hline$\sigma_{\mathrm{cm}}(\mathrm{MPa})^{*}$ & $0.072-25$ & $0.045-50$ \\
\hline$\sigma_{\mathrm{cm}}(\mathrm{MPa})^{* *}$ & $1.321-23.163$ & $1.409-46.325$ \\
\hline $\mathrm{Em}_{\mathrm{m}}(\mathrm{MPa})$ & $152.52-4971.64$ & $240.05-7328.58$ \\
\hline $\mathrm{Ei}_{\mathrm{i}}(\mathrm{MPa})$ & 10000 & 10000 \\
\hline$\sigma_{3} \max$ & 12.5 & 12.5 \\
\hline
\end{tabular}

*Roclab çıktısında Genelleştirilmiş Hoek-Brown yenilme ölçütünde tek eksenli basma dayanımı **Roclab çıktısında Mohr-Coulomb yenilme ölçütünden tek eksenli basma dayanımı

\section{SAYISAL ANALIZZ SONUÇLARI (RESULTS OF NUMERICAL ANALYSIS)}

$\mathrm{Bu}$ bölümde sunulan düşey dairesel kesitli maden kuyularının beton tahkimat kalınlıklarının belirlenmesine yönelik parametrik sayısal çözümlemelerde, Phase2 yazılımı kullanılmıştır. Phase2 programı sonlu elemanlar yöntemine dayalı zemin veya kaya ortamında yapılan yeraltı ve yerüstü yapıları için düzlem birim şekil değiştirme durumunda iki boyutlu ve eksenel simetri durumunda kısmen üç boyutlu gerilme çözümlemeleri yapabilmektedir. Yeraltı açıklıkları için beton, püskürtme 
beton, kaya saplaması, çelik tahkimat ve bunların kombinasyonlarından oluşan tahkimatlar için gerilme çözümlemeleri yapılmaktadır. Bu yazılım için bir model hazırlanmıştır. Bu modelde dairesel kesitli kuyu çapının (2r) 9 m olduğu kabul edilmiştir. Modeli çevreleyen dış sınır yatay ve düşey yönde yerdeğiştirmelere izin vermeyecek şekilde sabit mesnetlenmiştir. Kazı etki alanının modelin dış sınırından etkilenmemesi için modelin dış sınırının açıklığa olan uzaklığı kuyu çapının yaklaşık 10 katı olacak şekilde oluşturulmuştur. Bir başka ifade ile kuyu kesitinden etkilenecek bölgenin kuyu çevresinden itibaren 90 metrelik bölge olduğu ve bu bölgenin de Şekil 1'de görüldüğü üzere kuyu çevresine paralel olduğu var sayılmıştır.

Çizelge 2. Model için Phase2 yazılımında kullanılan beton özellikleri Table 2. Characteristics of concrete used for the model in Phase2 software

\begin{tabular}{|c|c|c|}
\hline Elastik özellikler & $\begin{array}{l}\text { Young Modülü (MPa) } \\
\text { Poisson Oran }\end{array}$ & $\begin{array}{c}28000 \\
0.2\end{array}$ \\
\hline \multirow{4}{*}{ Dayanım parametreleri } & Basma Dayanımı - $\sigma_{c c}($ En büyük) (MPa) & 20 \\
\hline & Basma Dayanımı (Kalıcı) (MPa) & 5 \\
\hline & Çekme Dayanımı (En büyük) (MPa) & 1.6 \\
\hline & Çekme Dayanımı (Kalıcı) (MPa) & 0 \\
\hline Doğrusal tür & Beam & Timoshanko \\
\hline Geometri & Kalınlık & 0.152 \\
\hline
\end{tabular}

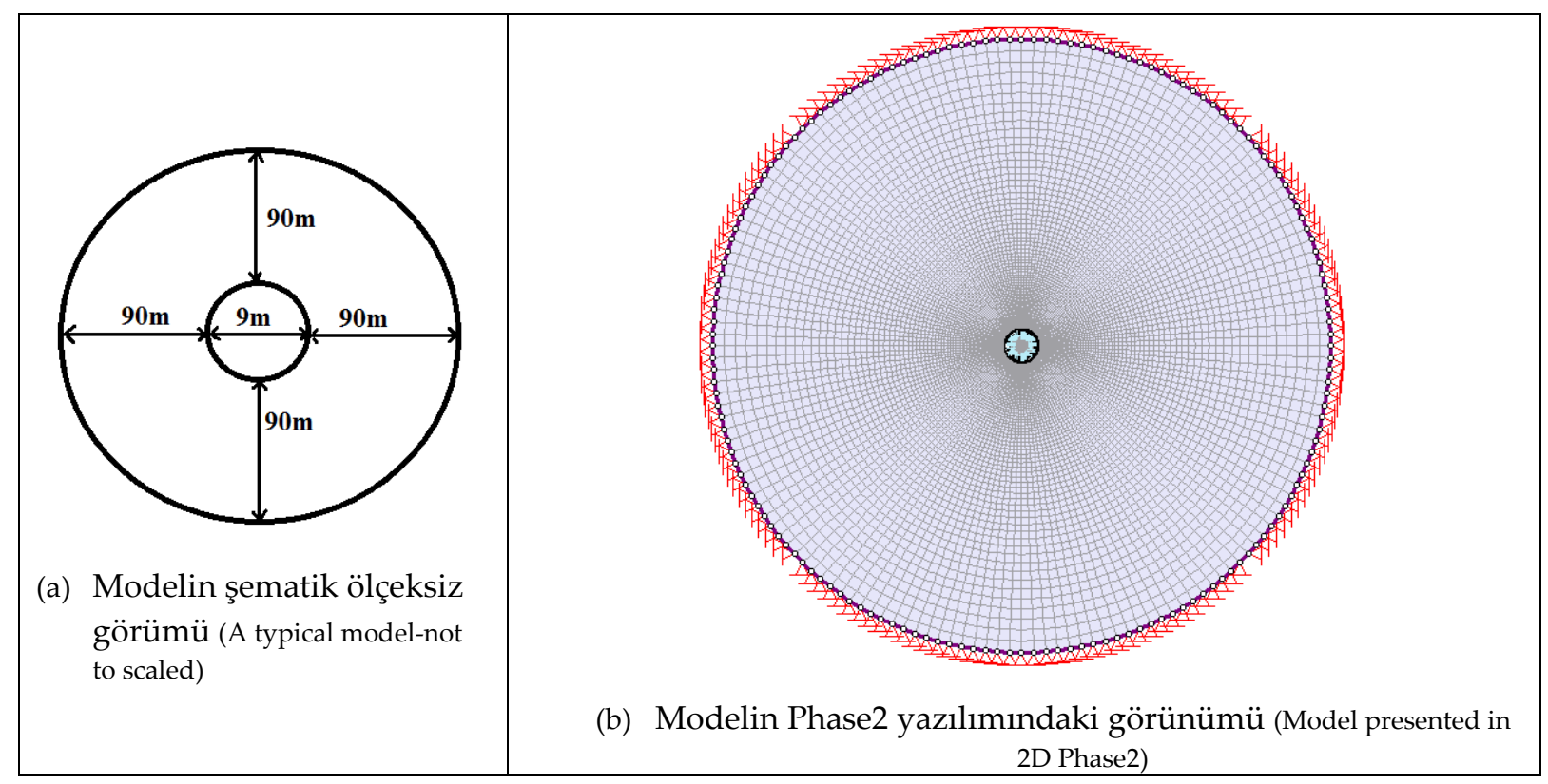

Şekil 1. İki boyutlu sayısal analizde kullanılan model

Figure 1. Model used in 2D numerical analysis

Hazırlanan modelde sonlu elemanlar ağ (mesh) tipi radial ve element tipi 4 noded quadrilaterals seçilmiştir. Birincil gerilmelerin tüm bileşenlerinin eşit olduğu $\left(\mathrm{P}_{0}=\mathrm{P}_{\mathrm{v}}=\mathrm{Ph}_{1}=\mathrm{Ph}_{2}\right)$ yani hidrostatik birincil gerilme alanı varsayılmıştır. Bu çalışmada derinlik (Z) $100 \mathrm{~m}, 300 \mathrm{~m}, 500 \mathrm{~m}, 700 \mathrm{~m}$ ve $900 \mathrm{~m}$ alındığ sabit arazi gerilmeleri sırasıyla $2.5 \mathrm{MPa}, 7.5 \mathrm{MPa}$, $12.5 \mathrm{MPa}$, $17.5 \mathrm{MPa}$ ve $22.5 \mathrm{MPa}$ olduğu aşağıda verilen temel eşitlikten hesaplanmıştır.

$$
\mathrm{P}_{0}=\mathrm{Z} \gamma
$$


Burada $\mathrm{P}_{0}$, düşey birincil gerilme $(\mathrm{MPa}) ; \mathrm{Z}$, derinlik $(\mathrm{m}) ; \gamma$, birim hacim ağırlığı $\left(\mathrm{MN} / \mathrm{m}^{3}\right)$ dır. Tahkimatlı ve tahkimatsız koşullarda yapılan sayısal analizlerde tahkimatsız durum için 2 aşama (stage), tahkimatlı durum için 3 aşama (stage) planlanmıştır. Tahkimatsız durumda birinci aşama kazı öncesi olurken ikinci aşama kazı sonrası ancak tahkimat yapılmamış durumu yansıtmaktadır. Tahkimatlı durumda birinci aşama kazı öncesi, ikinci aşama kazı sonrası (tahkimatsız) iken üçüncü aşamada tahkimatın yapıldığı var sayılmıştır. Bu duruma göre beklenen yerdeğiştirmenin (U), kazı öncesinde \%0 olacağı (Stage-1), kazı yapıldıktan sonra (tahkimat öncesinde) \%70 olacağ (Stage-2), tahkimat sonrasında ise \%30 (Stage-3) olacağı kabul edilmiştir (Geniş ve Acun, 2015; Geniş ve Derin, 2016).

Yukarıda belirtilen parametrelere göre sadece derinlik $100 \mathrm{~m}$ için tek eksenli basma dayanımına $\left(\sigma_{\mathrm{ci}}\right)$ ait 50MPa için toplam 20 adet sayısal analize konu olan senaryo oluşmaktadır. Analiz edilen diğer derinliklerde dikkate alınırsa $(Z=300 \mathrm{~m}, 500 \mathrm{~m}, 700 \mathrm{~m}$ ve $900 \mathrm{~m})$ ayrı ayrı analize tabi tutulan toplamda 100 adet senaryo ortaya çıkmaktadır. Ancak her bir senaryo için optimum beton tahkimat kalınlığını belirleyebilmek amacıyla yaklaşık $10 \mathrm{kez}$ sayısal analiz yapılmıştır. Her bir analizde beton tahkimat kalınlığı Phase2 (Rocscience, 2002) yazılımına girilmiş bu tahkimatın yenilip yenilmediği kontrol edilmiştir. Eğer beton tahkimat yenilmiş ise bir sonraki analizde beton tahkimat kalınlı̆̆ artırılmıştır. Sonuç olarak 100 adet senaryo için optimum beton kalınlığını bulmak amacıyla toplamda yaklaşık 1000 adet sayısal analiz gerçekleştirilmiştir. Ayrıca bu 100 adet senaryo için tahkimatsız koşulu altında analizler de yapılmıştır.

Takip eden bölümde tahkimatlı koşul altında belirlenen 100 adet senaryodan sadece bir tanesi aşağıda tipik bir örnek olarak hazırlanmıştır. Bu örnek çözümde kuyu cidarındaki örselenme durumu, sırasıyla (D) 0 ve 0.5 olarak alınmıştır.

Bu makale de sunmak amacıyla hazırlanan iki örnek Şekil 2, 3, 4 ve 5'te sunulmuştur. İlk örnek kuyu kazısında patlatmadan kaynaklanan örselenme hasarının $\mathrm{D}=0$ olması durumunda yapılan analizlerde derinlik $(Z) 100 \mathrm{~m}$, tek eksenli basma dayanımı $\left(\sigma_{\mathrm{ci}}\right) 50 \mathrm{MPa}$, Yeniden Düzenlenen Kaya Kütle İndeksi (MRMR) 40 alınmıştır. Bu koşul altında ilk önce beton tahkimat kalınlığı ( $\left.\mathrm{t}_{c}\right)$ rastgele $0.01 \mathrm{~m}$ alınmıştır. Bu durum için yapılan sayısal analiz sonuçları en büyük asal gerilme $\left(\sigma_{1}\right)$ ve toplam yerdeğiştirme $(\mathrm{U})$ için sırasıyla Şekil 2 ve $3^{\prime}$ de sunulmuştur. Bu tasarım çıktılarına göre kuyu cidarında $90^{\circ}$ ara ile tanımlanan A, B, C ve D noktalarında oluşan en büyük asal gerilme $\left(\sigma_{1}\right)$, toplam yerdeğiştirme $(U)$, yenilme bölgesi (\%) ve dayanım faktörü (SF) Çizelge 3'de görülmektedir. Bu koşul altında beton tahkimatta yenilme görülmemiştir.

İkinci örnek kuyu kazısında patlatmadan kaynaklanan örselenme hasarının $\mathrm{D}=0.5$ olması durumunda yapılan analizlerde derinlik $(Z) 100 \mathrm{~m}$, tek eksenli basma dayanımı $\left(\sigma_{\mathrm{ci}}\right) 50 \mathrm{MPa}$, Yeniden Düzenlenen Kaya Kütle İndeksi (M-RMR) 40 koşulu altında beton tahkimat kalınlığ $\left(\mathrm{t}_{c}\right)$ rastgele 0.074m alınmıştır. Bu durum için yapılan sayısal analiz sonuçları sırasıyla Şekil 4 ve 5'de sunulmuştur. Bu tasarım çıktılarına göre kuyu cidarında oluşan en büyük asal gerilme $\left(\sigma_{1}\right)$, toplam yerdeğiştirme (U), yenilme bölgesi (\%) ve dayanım faktörü (SF) Çizelge 4'de verilmiştir. Bu koşulu altında beton tahkimatta her hangi bir yenilmenin olmadığı tespit edilmiştir.

\section{BETON TAHKIMAT KALINLIKLARININ BELİRLENMESI İÇİN BİR YAKLAŞIMIN GELISSTIRILLMESI (DEVELOPMENT OF AN APPROACH FOR DETERMINING OF CONCRETE SUPPORT THICKNESS)}

Phase2 yazılımı yardımıyla yapılan analizlere bağlı ilk değerlendirme 1şığında Şekil 6 ve 7 hazırlanmıştır. Phase2 programı kullanılarak yapılan sayısal analizlere göre M-RMR değeri arttıkça beton tahkimat kalınlıklarının azaldığı, ayrıca derinlik arttıkça beton tahkimat kalınlıklarının buna karşı arttığı gözlenmiştir (Şekil 6 ve 7). 


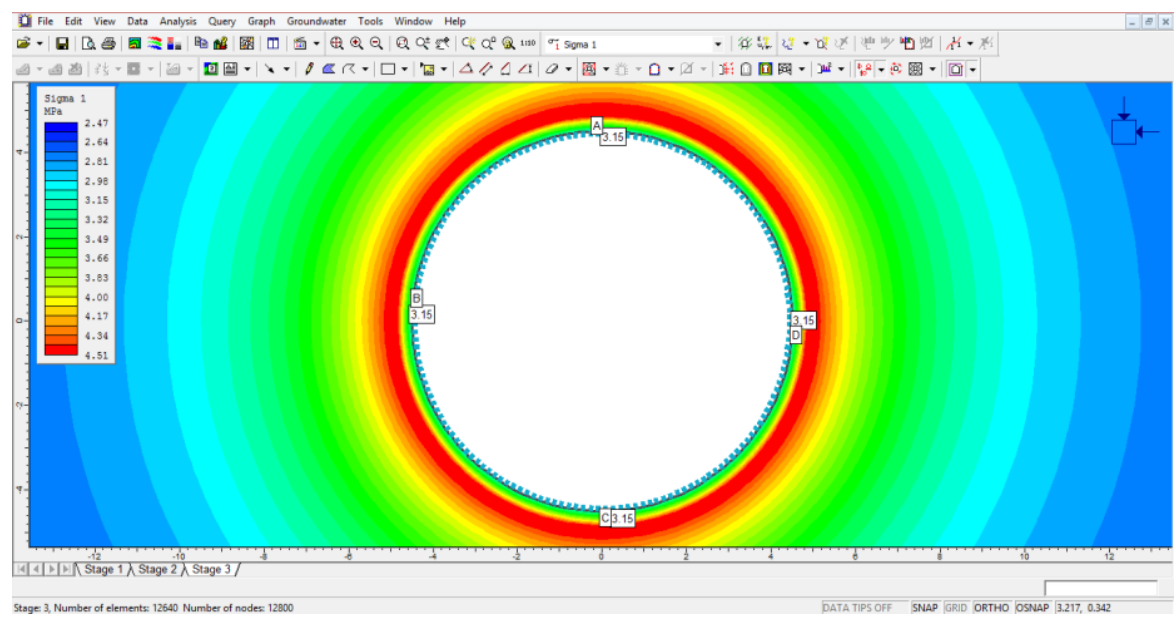

Şekil 2. $Z=100 \mathrm{~m}, \sigma_{\mathrm{ci}}=50 \mathrm{MPa}, \mathrm{M}-\mathrm{RMR}=40$ ve $\mathrm{D}=0$ koşulunda $\mathrm{t}_{\mathrm{c}}=0.01 \mathrm{~m}$ için en büyük asal gerilme $(\sigma 1, \mathrm{MPa})^{\prime}$ ye göre Phase2 analiz çıtısı

Figure 2. According to $\sigma_{1}(\mathrm{MPa})$, to Phase 2 analysis output for $t c=0.01 \mathrm{~m}$ under condition $\mathrm{Z}=100 \mathrm{~m}, \sigma_{c i}=50 \mathrm{MPa}, M-R M R=40$ and $D=0$

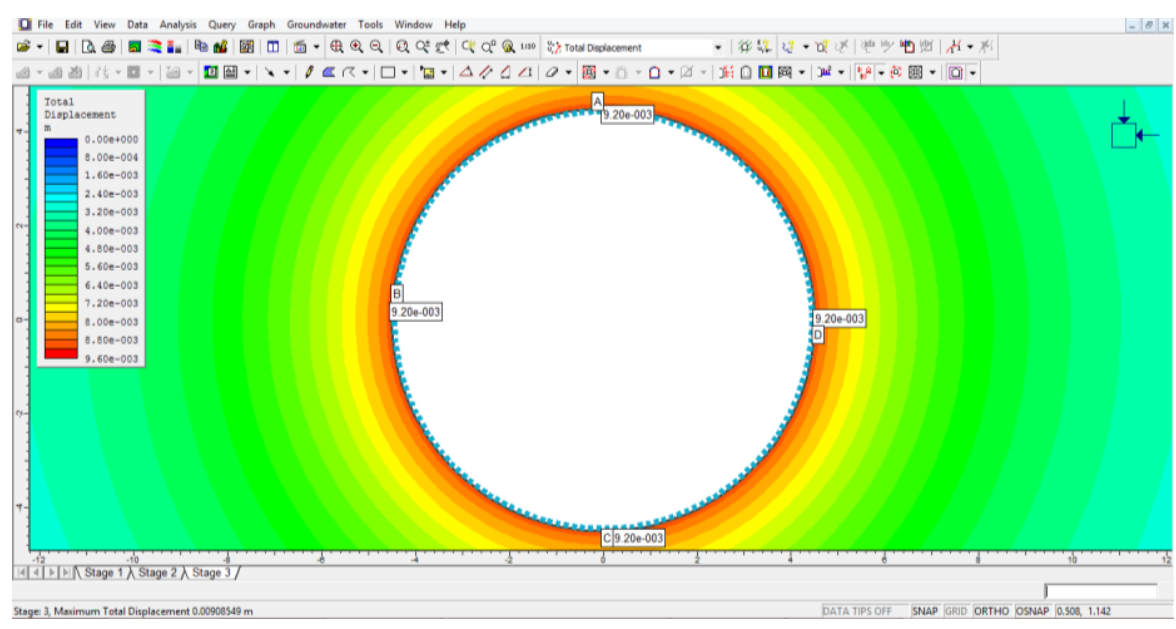

Şekil 3. $Z=100 \mathrm{~m}, \sigma_{\mathrm{ci}}=50 \mathrm{MPa}, \mathrm{M}-\mathrm{RMR}=40$ ve $\mathrm{D}=0$ koşulunda $\mathrm{t}_{\mathrm{c}}=0.01 \mathrm{~m}$ için yerdeğiştirme $(\mathrm{U}, \mathrm{mm})^{\prime}$ ye göre Phase2 analiz çıtısı

Figure 3. According to $U(\mathrm{~mm})$, Phase 2 analysis output for $t_{c}=0.01$ under condition $Z=100 \mathrm{~m}, \sigma_{\mathrm{ci}}=50 \mathrm{MPa}, \mathrm{M}-\mathrm{RMR}=40$ and $\mathrm{D}=0$

Çizelge 3. $\mathrm{Z}=100 \mathrm{~m}, \sigma_{\mathrm{ci}}=50 \mathrm{MPa}, \mathrm{M}-\mathrm{RMR}=40$ ve $\mathrm{D}=0$ koşulunda $\mathrm{t}_{\mathrm{c}}=0.01 \mathrm{~m}$ için sayısal analiz sonuçları Table 3. The numerical analysis results for $t_{c}=0.01 \mathrm{~m}$ under condition $\mathrm{Z}=100 \mathrm{~m}, \sigma_{c i}=50 \mathrm{MPa}, M-R M R=40$ and $D=0$

\begin{tabular}{|c|c|c|c|c|c|c|}
\hline $\begin{array}{l}\text { Aşama } \\
\text { (Stage) }\end{array}$ & $\begin{array}{c}\text { Kuyu } \\
\text { Cidarındaki } \\
\text { Analiz Noktası }\end{array}$ & (MPa) & (cm) & $\begin{array}{c}\text { Dayanım } \\
\text { Faktörü } \\
\text { (SF) }\end{array}$ & $\begin{array}{c}\text { Kaya Kütlesinde } \\
\text { Yenilme Bölgesi } \\
\text { Kalınlığı (m) }\end{array}$ & $\begin{array}{l}\text { Beton Tahkimatta } \\
\text { Yenilme Bölgesi } \\
\text { Kalınlığı (m) }\end{array}$ \\
\hline \multirow{5}{*}{$\begin{array}{c}\text { Tahkimatsız } \\
\text { Aşama-2 }\end{array}$} & $\mathrm{A}$ & 2.10 & 0.945 & 1.04 & \multirow{4}{*}{$\begin{array}{c}0.457 \\
(\mathrm{YES}=320)\end{array}$} & \multirow{4}{*}{-} \\
\hline & B & 2.10 & 0.945 & 1.04 & & \\
\hline & C & 2.10 & 0.945 & 1.04 & & \\
\hline & $\mathrm{D}$ & 2.10 & 0.945 & 1.04 & & \\
\hline & A & 2.29 & 0.630 & 1.04 & \multirow{4}{*}{$\begin{array}{c}0.271 \\
(\mathrm{YES}=160)\end{array}$} & \multirow{4}{*}{-} \\
\hline \multirow{3}{*}{$\begin{array}{c}\text { Tahkimatlı } \\
\text { Aşama-2 }\end{array}$} & B & 2.29 & 0.630 & 1.04 & & \\
\hline & $\mathrm{C}$ & 2.29 & 0.630 & 1.04 & & \\
\hline & $\mathrm{D}$ & 2.29 & 0.630 & 1.04 & & \\
\hline \multirow{4}{*}{$\begin{array}{c}\text { Tahkimatlı } \\
\text { Aşama-3 }\end{array}$} & A & 3.15 & 0.920 & 1.04 & \multirow{4}{*}{$\begin{array}{c}0.457 \\
(\mathrm{YES}=320)\end{array}$} & \multirow{4}{*}{$\begin{array}{c}0 \\
(\mathrm{YES}=0)\end{array}$} \\
\hline & B & 3.15 & 0.920 & 1.04 & & \\
\hline & C & 3.15 & 0.920 & 1.04 & & \\
\hline & D & 3.15 & 0.920 & 1.04 & & \\
\hline
\end{tabular}

YES: Yenilen Element Sayısı 


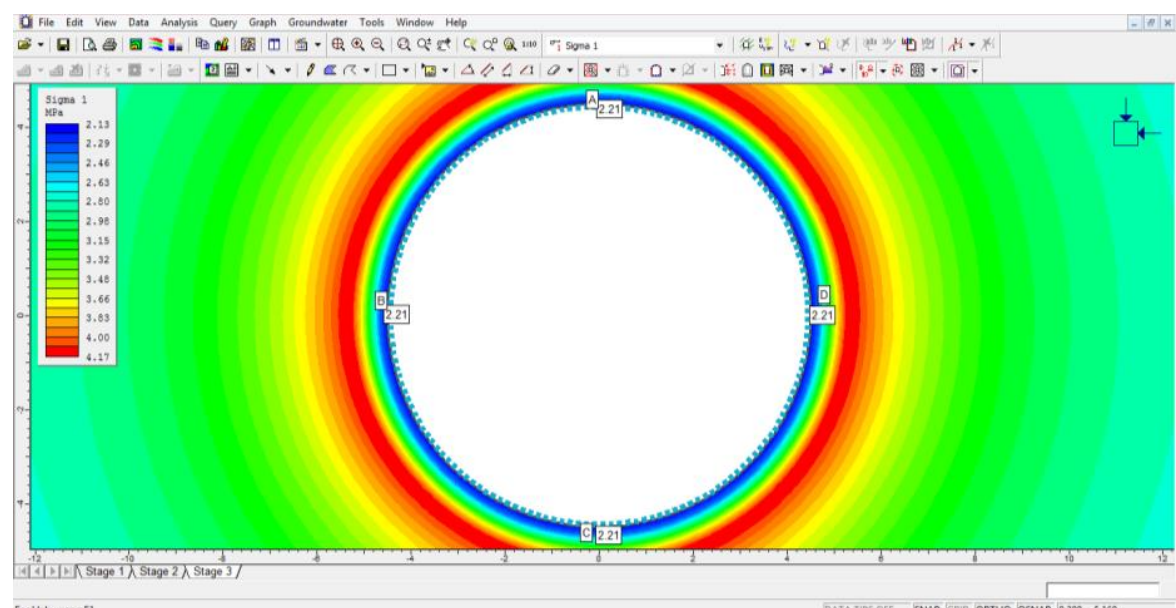

Şekil 4. $Z=100 \mathrm{~m}, \sigma_{\mathrm{ci}}=50 \mathrm{MPa}, \mathrm{M}-\mathrm{RMR}=40$ ve $\mathrm{D}=0.5$ koşulunda $\mathrm{t}_{\mathrm{c}}=0.074 \mathrm{~m}$ için en büyük asal gerilme $\left(\sigma_{1}, \mathrm{MPa}\right)^{\prime} \mathrm{ye}$ göre Phase2 analiz çıtısı

Figure 4. According to $\sigma_{1}(\mathrm{MPa})$, to Phase 2 analysis output for $t c=0.074 \mathrm{~m}$ under condition $\mathrm{Z}=100 \mathrm{~m}, \sigma_{c i}=50 \mathrm{MPa}$, $M-R M R=40$ and $D=0.5$

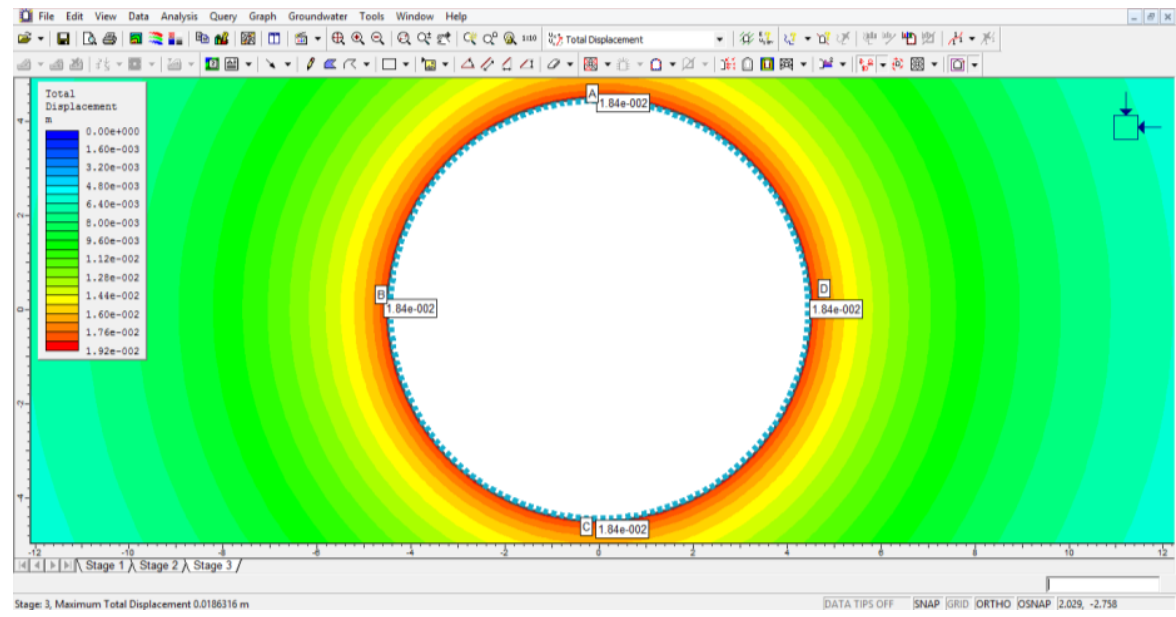

Şekil 5. $Z=100 \mathrm{~m}, \sigma_{\mathrm{ci}}=50 \mathrm{MPa}, \mathrm{M}-\mathrm{RMR}=40$ ve $\mathrm{D}=0.5$ koşulunda $\mathrm{t}_{\mathrm{c}}=0.074 \mathrm{~m}$ için yerdeğiştirme $(\mathrm{U}, \mathrm{mm})^{\prime}$ ye göre Phase 2 analiz çıktısı

Figure 5. According to $U(\mathrm{~mm})$, Phase 2 analysis output for $t_{c}=0.074$ under condition $Z=100 \mathrm{~m}, \sigma_{c i}=50 \mathrm{MPa}$, $M-R M R=40$ and $D=0.5$

Çizelge 4. $\mathrm{Z}=100 \mathrm{~m}, \sigma_{\mathrm{ci}}=50 \mathrm{MPa}, \mathrm{M}-\mathrm{RMR}=40$ ve $\mathrm{D}=0.5$ koşulunda $\mathrm{t}_{\mathrm{c}}=0.074 \mathrm{~m}$ için sayısal analiz sonuçları Table 4. The numerical analysis results for $t_{c}=0.074 \mathrm{~m}$ under condition $\mathrm{Z}=100 \mathrm{~m}, \sigma_{c i}=50 \mathrm{MPa}, \mathrm{M}-\mathrm{RMR}=40$ and $\mathrm{D}=0.5$

\begin{tabular}{|c|c|c|c|c|c|c|}
\hline $\begin{array}{l}\text { Aşama } \\
\text { (Stage) }\end{array}$ & $\begin{array}{c}\text { Kuyu } \\
\text { Cidarındaki } \\
\text { Analiz Noktası }\end{array}$ & $\begin{array}{c}\sigma_{1} \\
(\mathrm{MPa})\end{array}$ & $\begin{array}{c}\mathrm{U} \\
(\mathrm{cm})\end{array}$ & $\begin{array}{c}\text { Dayanım } \\
\text { Faktörü } \\
\text { (SF) }\end{array}$ & $\begin{array}{l}\text { Kaya Kütlesinde } \\
\text { Yenilme Bölgesi } \\
\text { Kalınlığı (m) }\end{array}$ & $\begin{array}{c}\text { Beton Tahkimatta } \\
\text { Yenilme Bölgesi } \\
\text { Kalınlığı (m) }\end{array}$ \\
\hline \multirow{5}{*}{$\begin{array}{c}\text { Tahkimatsız } \\
\text { Aşama-2 }\end{array}$} & A & 1.05 & 2.40 & 1.04 & \multirow{4}{*}{$\begin{array}{c}1.286 \\
(\mathrm{YES}=960)\end{array}$} & \multirow{4}{*}{-} \\
\hline & B & 1.05 & 2.40 & 1.04 & & \\
\hline & C & 1.05 & 2.40 & 1.04 & & \\
\hline & D & 1.05 & 2.40 & 1.04 & & \\
\hline & A & 1 & 1.56 & 1.04 & \multirow{4}{*}{$\begin{array}{c}0.858 \\
(\mathrm{YES}=640)\end{array}$} & \multirow{4}{*}{-} \\
\hline \multirow{3}{*}{$\begin{array}{c}\text { Tahkimatlı } \\
\text { Aşama-2 }\end{array}$} & B & 1 & 1.56 & 1.04 & & \\
\hline & C & 1 & 1.56 & 1.04 & & \\
\hline & $\mathrm{D}$ & 1 & 1.56 & 1.04 & & \\
\hline \multirow{4}{*}{$\begin{array}{c}\text { Tahkimatlı } \\
\text { Aşama-3 }\end{array}$} & A & 2.21 & 1.84 & 1.30 & \multirow{4}{*}{$\begin{array}{c}0.854 \\
(\mathrm{YES}=620)\end{array}$} & \multirow{4}{*}{$\begin{array}{c}0 \\
(\mathrm{YES}=0)\end{array}$} \\
\hline & B & 2.21 & 1.84 & 1.30 & & \\
\hline & C & 2.21 & 1.84 & 1.30 & & \\
\hline & $\mathrm{D}$ & 2.21 & 1.84 & 1.30 & & \\
\hline
\end{tabular}

YES: Yenilen Element Sayısı 
İki boyutlu sayısal çözümleme yapabilen Phase2 yazılımı ile kurgulanan modelde dairesel kuyu kesiti cidarında sırasıyla belirlenen yenilme bölgesi kalınlığı $\left(h_{t}\right)$ ve yerdeğiştirme $(U)$ değerleri her bir koşul için (farklı M-RMR değerlerinde) kritik beton tahkimat kalınlığında belirlenmiştir. Hazırlanan veri tabanı kullanılarak bir seri grafikler hazırlanmıştır.

Makineler ile yapılan kazıya dayalı hasarsız $(D=0)$ ve patlatmaya dayalı hasarlı kazıya $(D=0.5)$ bağlı olarak düşey kuyu etrafında oluşan yenilme bölgesi, bu çalışmada ht olarak tanımlanmıştır (Şekil 8). Kaya kütlesine, derinliğe ve beton tahkimat kalınlığına bağlı olarak ht kalınlığı (Şekil 8) azalmakta yada artmaktadır.Bu çalışma için tipik örnek olarak hazırlanan $Z=100 \mathrm{~m}$ ve $\mathrm{D}=0$ koşulu altında belirlenen davranışlar Şekil 9'da sunulmuştur. Hazırlanan grafiklerden görüldüğü üzere (Şekil 9a) M-RMR değerleri küçüldükçe yenilme bölgesi kalınlığı $\left(\mathrm{h}_{\mathrm{t}}\right)$ artmaktadır. M-RMR'ye bağlı oluşan yenilme bölgesi kalınlıklarının $\left(h_{t}\right)$ artması durumunda (Şekil 9b) gerekli olan beton kalınlıkları artmaktadır. M-RMR değerleri artıkça belirlenen optimum beton kalınlıklarında kuyu cidarında beklenen yerdeğiştirmenin azaldığı belirlenmiştir (Şekil 9c). Belirlenen bu beton kalınlıklarında ise azalan M-RMR değerlerine bağlı olarak tahkimatın müsaade ettiği yerdeğiştirme değerlerinin büyüdüğü anlaşılmaktadır (Şekil 9d).

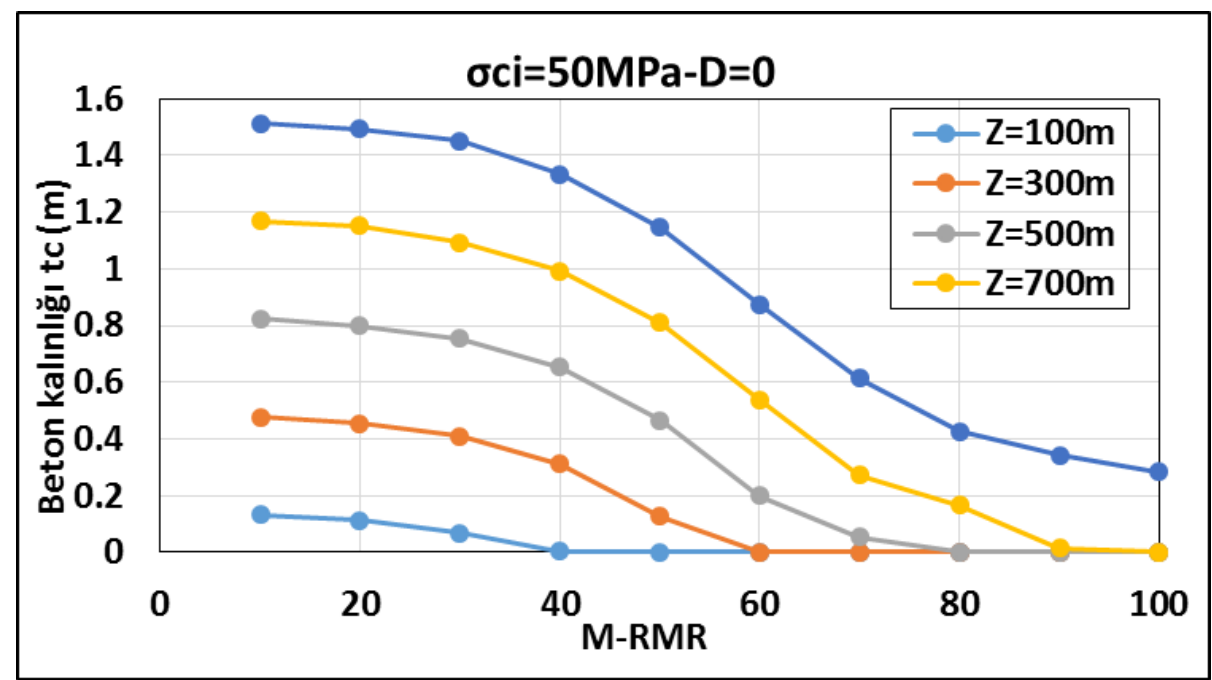

Şekil 6. $\mathrm{D}=0$ ve $\sigma_{\mathrm{ci}}=50 \mathrm{MPa}$ koşulu altında $\mathrm{M}-\mathrm{RMR}$ 'ye bağlı farklı derinlikte beton kalınlık değişimi Figure 6. The concrete thickness behavior based on $M-R M R$ to different depths under condition $D=0 \sigma_{c i}=50 \mathrm{MPa}$

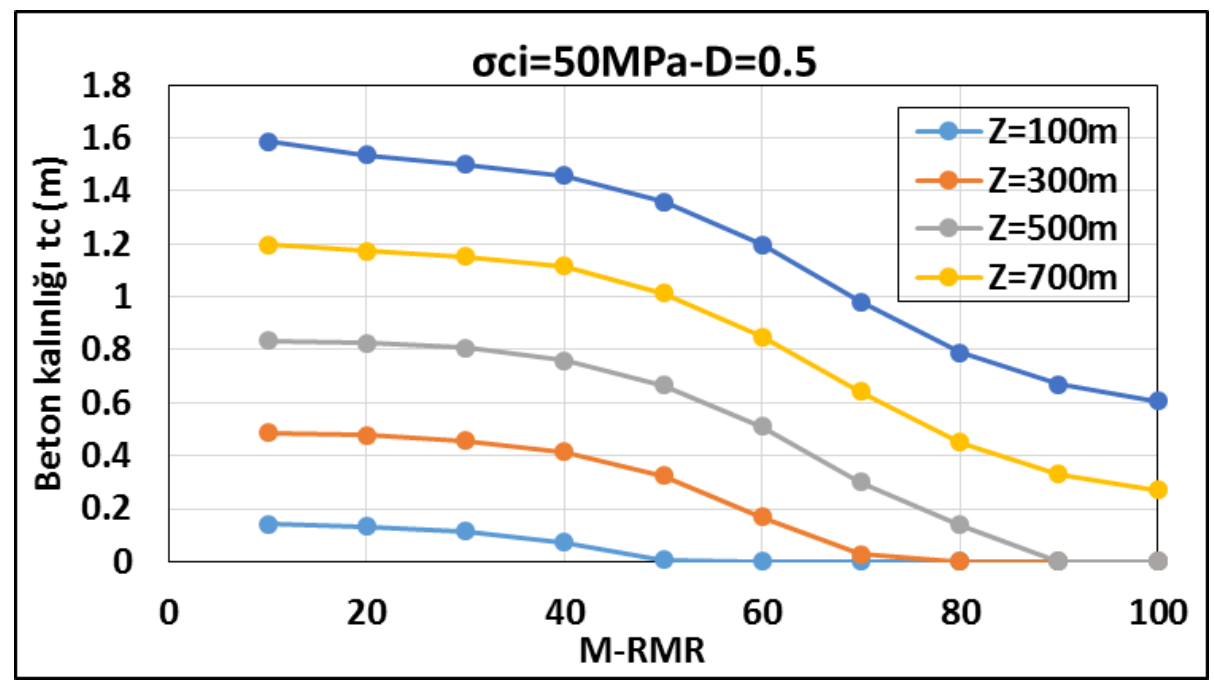

Şekil 7. $\mathrm{D}=0.5$ ve $\sigma_{\mathrm{ci}}=50 \mathrm{MPa}$ koşulu altında $\mathrm{M}-\mathrm{RMR}$ ye bağlı farklı derinlikte beton kalınlık değişimi Figure 7. The concrete thickness behavior based on M-RMR to different depths under condition $D=0.5 \sigma_{c i}=50 \mathrm{MPa}$ 


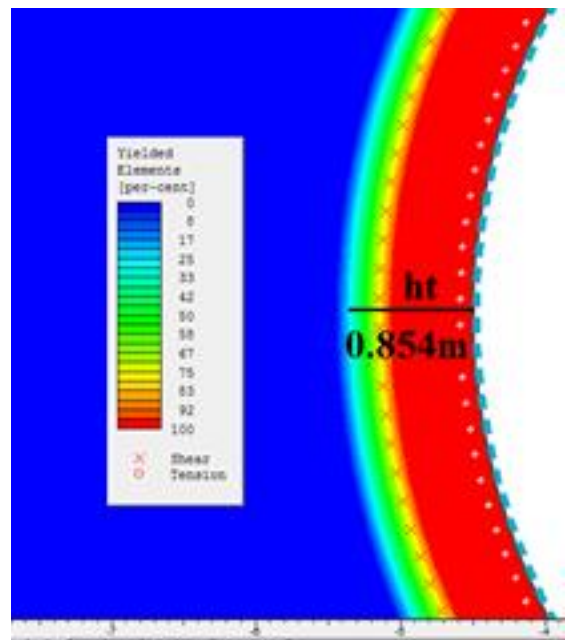

$\mathrm{Z}=100 \mathrm{~m}, \sigma_{\mathrm{ci}}=50 \mathrm{MPa}, \mathrm{M}-\mathrm{RMR}=40$ ve $\mathrm{D}=0.5$ koşulunda $\mathrm{t}_{\mathrm{c}}=0.074 \mathrm{~m}$ için yenilme bölgesi kalınlığını $\left(\mathrm{h}_{\mathrm{t}}\right)$ gösteren Phase2 analiz çıktısı

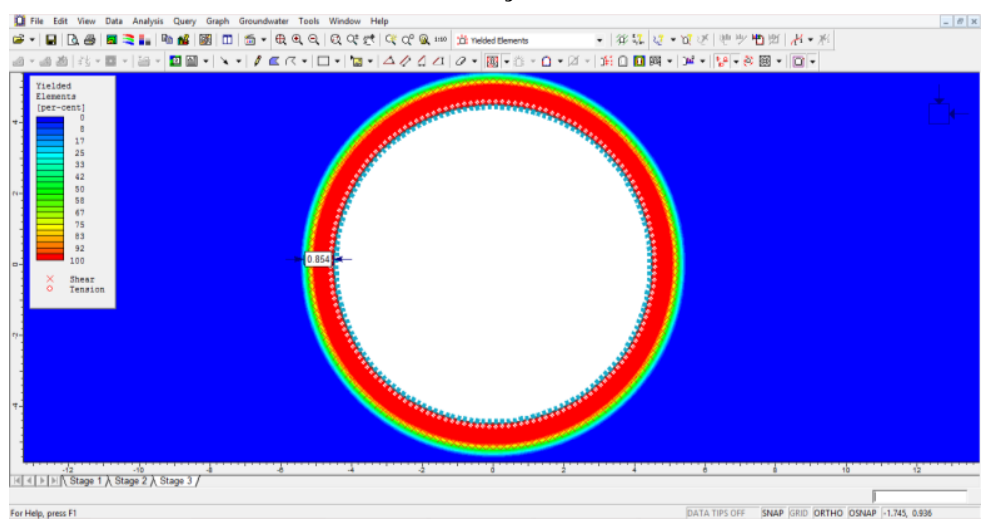

Şekil 8. Yenilme bölgesi kalınlığını $\left(h_{t}\right)$ gösteren tipik bir şekil Figure 8. A typical figure for thickness of yielded region

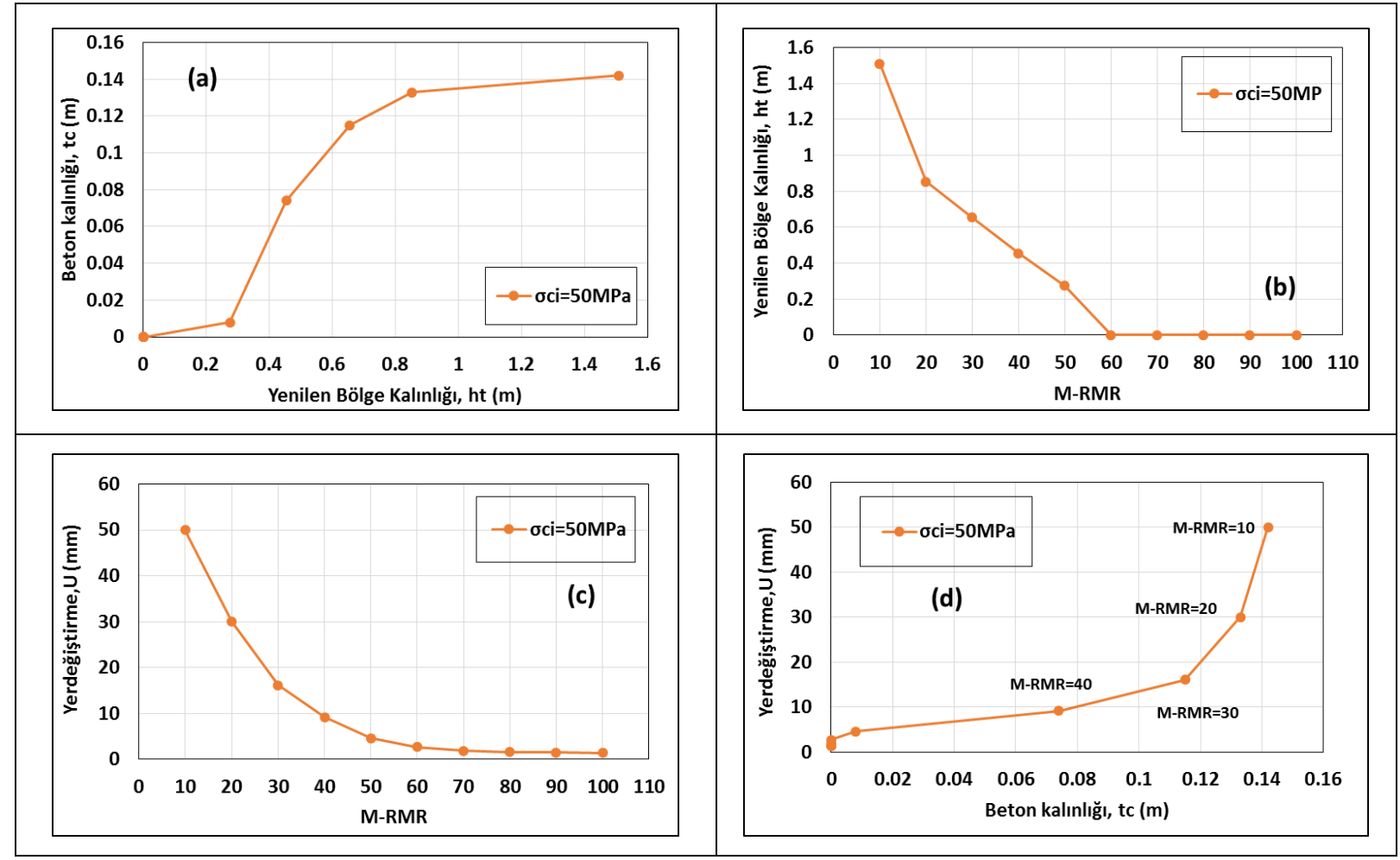

Şekil 9. $Z=100 \mathrm{~m}$ ve $D=0$ koşulunda kuyu etrafında oluşan $h_{t}, t_{c}$, ve $U$ davranışı Figure 9. $h_{t}, t_{c}, U$ behavior formed around the shaft under conditions $Z=100$ and $D=0$

Yukarıda sunulan tipik grafikler (Şekil 9) incelenerek bütünleyici bir yaklaşım geliştirilmeye çalışılmıştır. Bu yaklaşımın 4 aşamadan oluşması planlanmıştır. Bu yaklaşımda bir mühendisin abak üzerinden kolayca tasarım sonuçlarına ulaşması hedeflenmiştir. $\mathrm{Bu}$ aşamalar aşağıda sırasıyla sunulmuştur. 
i. Aşama 1: M-RMR değerinin bilinmesi durumunda kuyu etrafında oluşan yenilme bölgesi kalınlığının $\left(h_{t}\right)$ belirlenmesi,

ii. Aşama 2: Belirlenen yenilme bölge kalınlığına $\left(h_{t}\right)$ bağlı olarak gerekli olan beton tahkimat kalınlığının $\left(t_{c}\right)$ belirlenmesi,

iii. Aşama 3: Tesbit edilen beton kalınlığına ( $\left.t_{c}\right)$ bağlı olarak müsaade edilmesi beklenen yerdeğiştirme $(\mathrm{U})$ miktarının belirlenmesi,

iv. Aşama 4: M-RMR değerine bağlı olarak belirlenen yerdeğiştirme (U) değerinin Aşama 3'den bulunan yerdeğiştirme değeriyle çakıştırılması.

Yukarıda ifade edilen algoritmayı gösteren tipik bir abak, $\mathrm{Z}=500 \mathrm{~m}, \mathrm{D}=0$ ve kaya dayanımı $\left(\sigma_{\mathrm{ci}}\right)$ $50 \mathrm{MPa}$ koşulu için hazırlanan bütünleyici yaklaşım Şekil $10^{\prime}$ da verilmiştir. Bu şekilde grafiği hazırlayabilmek için tc ve U değerleri negatif (-) alınmıştır. Gerçekte bu değerler pozitif değer taşımaktadır.

Şekil 10'da sunulan abakta oklarla saatin ters yönünde hareket edilerek M-RMR değeri 20 iken tasarım mühendisi bu abaktan kolaylıkla kuyu etrafındaki yenilme bölgesi kalınlığının (ht) $400.6 \mathrm{~cm}$, bunu tahkim etmek için gerekli beton tahkimat kalınlığının $\left(t_{c}\right) 79.9 \mathrm{~cm}$, bu tahkimatın uygulaması neticesinde oluşacak yerdeğiştirme (U) miktarının ise $285 \mathrm{~mm}$ olacağını belirleyebilecektir.

Şekil 10'da sunulan abaktan farklı M-RMR değerler için $h_{t}, t_{c}$ ve $U$ değerleri belirlenerek aşağıdaki Çizelge 5 hazırlanmıştır. Farklı derinliklerde $(\mathrm{Z}=100 \mathrm{~m}, 300 \mathrm{~m}, 500 \mathrm{~m}, 700 \mathrm{~m}, 900 \mathrm{~m})$ elde edilen sayısal çözümleme sonuçlarına bağlı olarak Şekil 10'daki gibi toplam 10 adet abak geliştirilmiştir. Makalede yer sorunu olduğu için ayrı ayrı 10 abak verilmesi yerine her bir abaktan bulunan sonuçlar Çizelge 5'deki gibi sırasıyla Çizelge 6, 7, 8 ve 9'da sunulmuştur.

\section{$\mathrm{Z}=500 \mathrm{~m}, \mathrm{D}=0, \sigma c i=50 \mathrm{MPa}$ için beton kalınlığını belirleme abağı (ABAK-3)}

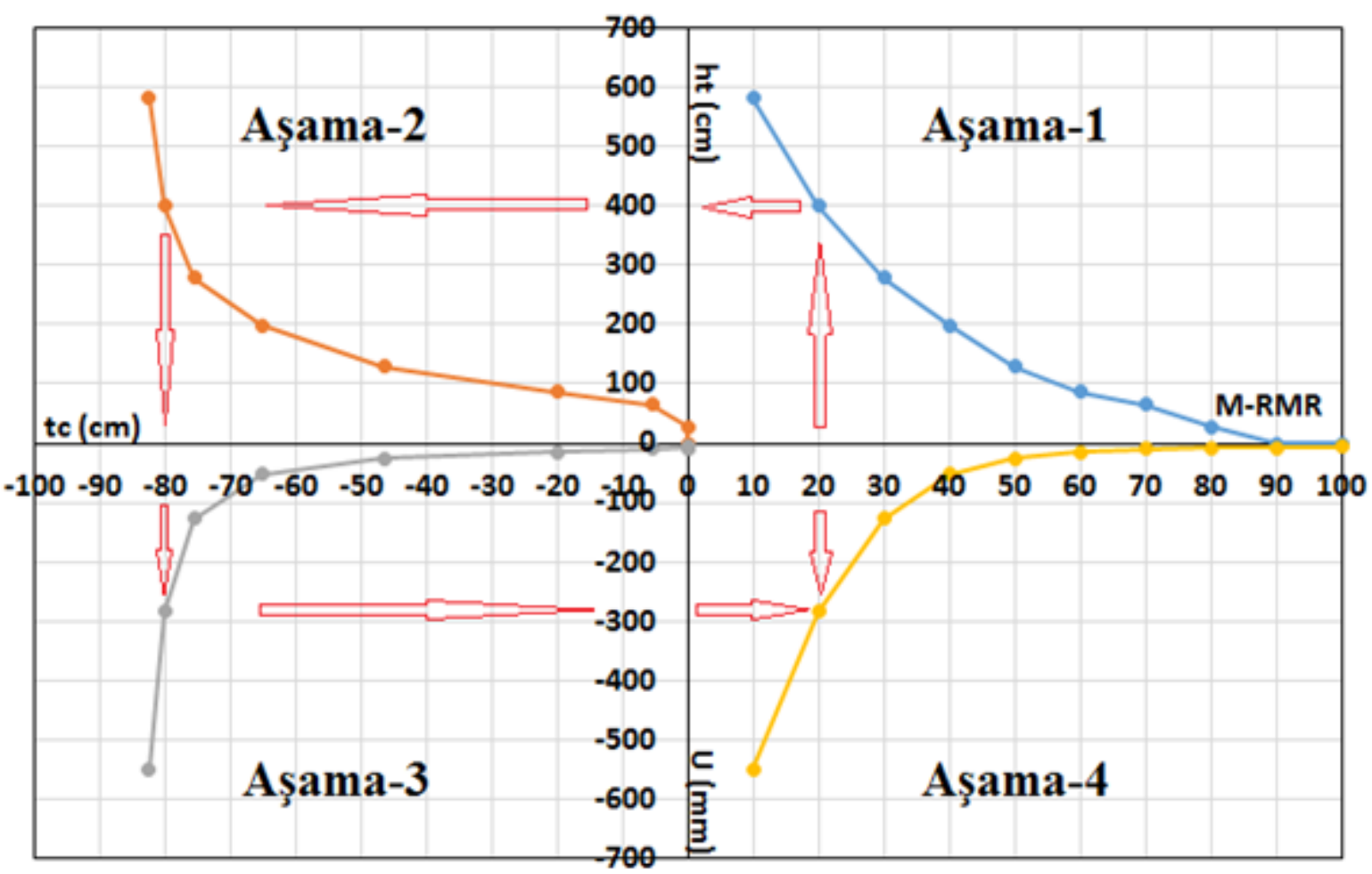

Şekil 10. $Z=500 \mathrm{~m}, \mathrm{D}=0$ ve kaya dayanımı $\left(\sigma_{\mathrm{ci}}\right) 50 \mathrm{MPa}$ koşulu altında bütünleyici yaklaşım Figure 10. The integrated approach under condition $\mathrm{Z}=500 \mathrm{~m}, \mathrm{D}=0$ and $\left(\sigma_{c i}\right) 50 \mathrm{MPa}$ 
Çizelge 5. $Z=500 \mathrm{~m}, \mathrm{D}=0, \mathrm{D}=0.5$ ve kaya dayanımı $\left(\sigma_{\mathrm{ci}}\right)$ 50MPa koşulu altında hazırlanan Şekil 10'dan elde edilen veriler

Table 5. The obtained data by Figure 10 under conditions $Z=500 \mathrm{~m}, D=0, D=0.5$ and $\left(\sigma_{c i}\right) 50 \mathrm{MPa}$

\begin{tabular}{|c|c|c|c|c|c|c|}
\hline \multirow{2}{*}{ M-RMR } & \multicolumn{3}{|c|}{$\mathrm{D}=0$ (ABAK-3) } & \multicolumn{3}{|c|}{$\mathrm{D}=0.5(\mathrm{ABAK}-4)$} \\
\hline & $h_{t}(\mathrm{~cm})$ & $t_{c}(\mathrm{~cm})$ & $\mathrm{U}(\mathrm{mm})$ & $h_{t}(\mathrm{~cm})$ & $t_{c}(\mathrm{~cm})$ & $\mathrm{U}(\mathrm{mm})$ \\
\hline 10 & 582.1 & 82.4 & 550.0 & 2054.4 & 83.4 & 3300.0 \\
\hline 20 & 400.6 & 79.9 & 285.0 & 1127.2 & 82.5 & 1200.0 \\
\hline 30 & 279.6 & 75.4 & 127.0 & 664.3 & 80.6 & 440.0 \\
\hline 40 & 199.4 & 65.2 & 52.5 & 401.0 & 7.6 & 165.0 \\
\hline 50 & 129.1 & 46.5 & 25.5 & 251.7 & 6.67 & 63.0 \\
\hline 60 & 86.1 & 19.9 & 14.4 & 151.8 & 5.11 & 28.5 \\
\hline 70 & 64.9 & 5.4 & 9.9 & 85.2 & 3.01 & 15.4 \\
\hline 80 & 26.9 & 0 & 8.05 & 26.8 & 1.4 & 11.5 \\
\hline 90 & 0 & 0 & 7.35 & 0 & 0 & 9.9 \\
\hline 100 & 0 & 0 & 6.9 & 0 & 0 & 9.6 \\
\hline
\end{tabular}

ht : Yenilme bölgesi kalınlığı, tc: Beton tahkimat kalınlığı, U : Beton tahkimatın müsaade edeceği yerdeğiştirme

Çizelge 6. $Z=100 \mathrm{~m}, \mathrm{D}=0, \mathrm{D}=0.5$ ve kaya dayanımı $\left(\sigma_{\mathrm{c} i}\right) 50 \mathrm{MPa}$ koşulu altında hazırlanan veriler Table 6 . The obtained data under conditions $Z=100 \mathrm{~m}, D=0, D=0.5$ and $\left(\sigma_{c i}\right) 50 \mathrm{MPa}$

\begin{tabular}{|c|ccc|ccc|}
\hline $\mathbf{M}-\mathbf{R M R}$ & \multicolumn{3}{|c}{$\mathbf{D = 0} \mathbf{( A B A K - 1 )}$} & \multicolumn{3}{c|}{$\mathbf{D = 0 . 5} \mathbf{( A B A K - 2 )}$} \\
$\mathbf{t}_{\mathbf{c}} \mathbf{( \mathbf { c m } )}$ & $\mathbf{U} \mathbf{( \mathbf { m m } )}$ & $\mathbf{h}_{\mathbf{t}} \mathbf{( \mathbf { c m } )}$ & $\mathbf{U} \mathbf{( \mathbf { m m } )}$ \\
\hline $\mathbf{1 0}$ & 151.0 & 13.2 & 50.0 & 337.8 & 14.2 & 99.0 \\
$\mathbf{2 0}$ & 85.4 & 11.3 & 30.0 & 225.7 & 13.3 & 63.0 \\
$\mathbf{3 0}$ & 65.6 & 6.8 & 16.1 & 151.6 & 11.5 & 34.5 \\
$\mathbf{4 0}$ & 45.5 & 0.2 & 9.2 & 85.4 & 7.4 & 18.4 \\
$\mathbf{5 0}$ & 27.6 & 0 & 4.6 & 46.2 & 0.8 & 9.9 \\
$\mathbf{6 0}$ & 0 & 0 & 2.7 & 27.2 & 0 & 5.25 \\
$\mathbf{7 0}$ & 0 & 0 & 1.84 & 0 & 0 & 3.15 \\
$\mathbf{8 0}$ & 0 & 0 & 1.54 & 0 & 0 & 2.4 \\
$\mathbf{9 0}$ & 0 & 0 & 1.43 & 0 & 0 & 2.04 \\
$\mathbf{1 0 0}$ & 0 & 0 & 1.38 & 0 & 0 & 1.92 \\
\hline
\end{tabular}

ht: Yenilme bölgesi kalınlığı, tc: Beton tahkimat kalınlığı, U : Beton tahkimatın müsaade edeceği yerdeğiştirme

Çizelge 7. $Z=300 \mathrm{~m}, \mathrm{D}=0, \mathrm{D}=0.5$ ve kaya dayanımı $\left(\sigma_{\mathrm{ci}}\right) 50 \mathrm{MPa}$ koşulu altında hazırlanan veriler Table 7. The obtained data under conditions $Z=300 \mathrm{~m}, D=0, D=0.5$ and $\left(\sigma_{c i}\right) 50 \mathrm{MPa}$

\begin{tabular}{|c|ccc|ccc|}
\hline \multirow{2}{*}{ M-RMR } & \multicolumn{3}{|c}{$\mathbf{D = 0}(\mathbf{A B A K}-\mathbf{5})$} & \multicolumn{3}{c|}{$\mathbf{D = 0 . 5}(\mathbf{A B A K}-\mathbf{6})$} \\
$\mathbf{t}_{\mathbf{t}} \mathbf{( \mathbf { c m } )}$ & $\mathbf{t}_{\mathbf{c}} \mathbf{( \mathbf { c m } )}$ & $\mathbf{U} \mathbf{( \mathbf { m m } )}$ & $\mathbf{h}_{\mathbf{t}} \mathbf{( \mathbf { c m } )}$ & $\mathbf{\mathbf { c m }} \mathbf{( \mathbf { m m } )}$ \\
\hline $\mathbf{1 0}$ & 368.4 & 47.6 & 230.0 & 1067.8 & 48.7 & 840.0 \\
$\mathbf{2 0}$ & 253.7 & 45.4 & 127.0 & 621.9 & 47.9 & 380.0 \\
$\mathbf{3 0}$ & 174.0 & 41.0 & 60.0 & 401.8 & 45.7 & 172.0 \\
$\mathbf{4 0}$ & 128.3 & 31.0 & 28.5 & 251.7 & 41.4 & 73.5 \\
$\mathbf{5 0}$ & 85.7 & 12.6 & 14.4 & 151.6 & 32.6 & 31.5 \\
$\mathbf{6 0}$ & 65.9 & 0 & 8.8 & 85.2 & 17.0 & 15.4 \\
$\mathbf{7 0}$ & 27.1 & 0 & 5.75 & 45.9 & 2.9 & 9.9 \\
$\mathbf{8 0}$ & 0 & 0 & 4.8 & 0 & 0 & 6.9 \\
$\mathbf{9 0}$ & 0 & 0 & 4.2 & 0 & 0 & 6.0 \\
$\mathbf{1 0 0}$ & 0 & 0 & 4.2 & 0 & 0 & 5.75 \\
\hline
\end{tabular}

ht : Yenilme bölgesi kalınlığı, tc: Beton tahkimat kalınlığı, U : Beton tahkimatın müsaade edeceği yerdeğiştirme 
Çizelge 8. $\mathrm{Z}=700 \mathrm{~m}, \mathrm{D}=0, \mathrm{D}=0.5$ ve kaya dayanımı $\left(\sigma_{\mathrm{ci}}\right) 50 \mathrm{MPa}$ koşulu altında hazırlanan veriler Table 8. The obtained data under conditions $Z=700 \mathrm{~m}, D=0, D=0.5$ and $\left(\sigma_{c i}\right) 50 \mathrm{MPa}$

\begin{tabular}{|c|c|c|c|c|c|c|}
\hline \multirow{2}{*}{ M-RMR } & \multicolumn{3}{|c|}{$\mathrm{D}=0$ (ABAK-7) } & \multicolumn{3}{|c|}{$\mathrm{D}=0.5(\mathrm{ABAK}-8)$} \\
\hline & $h_{t}(\mathrm{~cm})$ & $t_{c}(\mathrm{~cm})$ & $\mathrm{U}(\mathrm{mm})$ & $h_{t}(\mathrm{~cm})$ & $t_{c}(\mathrm{~cm})$ & $\mathrm{U}(\mathrm{mm})$ \\
\hline 10 & 850.4 & 116.9 & 1150.0 & 3091.9 & 119.8 & 7700.0 \\
\hline 20 & 543.3 & 115.3 & 500.0 & 1695.5 & 117.4 & 2700.0 \\
\hline 30 & 401.3 & 109.2 & 230.0 & 952.9 & 115.1 & 920.0 \\
\hline 40 & 274.9 & 99.2 & 92.0 & 542.3 & 111.7 & 300.0 \\
\hline 50 & 199.4 & 80.9 & 40.0 & 337.8 & 101.4 & 105.0 \\
\hline 60 & 129.1 & 53.9 & 20.7 & 225.1 & 84.8 & 46.0 \\
\hline 70 & 65.6 & 27.2 & 13.8 & 106.4 & 64.2 & 23.0 \\
\hline 80 & 46.2 & 16.5 & 11.0 & 46.1 & 45.2 & 15.4 \\
\hline 90 & 27.2 & 1.3 & 9.9 & 0 & 33.1 & 13.2 \\
\hline 100 & 0 & 0 & 9.9 & 0 & 27.1 & 12.1 \\
\hline
\end{tabular}

ht : Yenilme bölgesi kalınlığı, tc: Beton tahkimat kalınlığı, U: Beton tahkimatın müsaade edeceği yerdeğiştirme

Çizelge 9. $Z=900 \mathrm{~m}, \mathrm{D}=0, \mathrm{D}=0.5$ ve kaya dayanımı $\left(\sigma_{\mathrm{ci}}\right) 50 \mathrm{MPa}$ koşulu altında hazırlanan veriler Table 9. The obtained data under conditions $Z=900 \mathrm{~m}, D=0, D=0.5$ and $\left(\sigma_{c i}\right) 50 M P a$

\begin{tabular}{|c|c|c|c|c|c|c|}
\hline \multirow{2}{*}{ M-RMR } & \multicolumn{3}{|c|}{$\mathrm{D}=0$ (ABAK-9) } & \multicolumn{3}{|c|}{$\mathrm{D}=0.5(\mathrm{ABAK}-10)$} \\
\hline & $h_{t}(\mathrm{~cm})$ & $t_{c}(\mathrm{~cm})$ & $\mathrm{U}(\mathrm{mm})$ & $h_{t}(\mathrm{~cm})$ & $t_{c}(\mathrm{~cm})$ & $\mathrm{U}(\mathrm{mm})$ \\
\hline 10 & 1126.1 & 151.3 & 2070.0 & 3853.8 & 158.8 & 12700.0 \\
\hline 20 & 752.2 & 149.3 & 880.0 & 2265.0 & 153.5 & 5250.0 \\
\hline 30 & 504.1 & 145.2 & 330.0 & 1257.2 & 150.1 & 1540.0 \\
\hline 40 & 367.5 & 133.5 & 132.0 & 709.6 & 145.9 & 500.0 \\
\hline 50 & 251.1 & 114.7 & 55.0 & 435.1 & 135.8 & 161.0 \\
\hline 60 & 175.3 & 87.5 & 28.5 & 279.1 & 119.6 & 63.0 \\
\hline 70 & 106.3 & 61.3 & 17.6 & 150.7 & 98.2 & 31.5 \\
\hline 80 & 65.1 & 42.5 & 15.4 & 85.4 & 79.0 & 20.4 \\
\hline 90 & 26.9 & 34.3 & 12.1 & 28.3 & 66.9 & 16.1 \\
\hline 100 & 0 & 28.3 & 12.0 & 0 & 60.8 & 15.0 \\
\hline
\end{tabular}

ht : Yenilme bölgesi kalınlığı, tc : Beton tahkimat kalınlığı, U : Beton tahkimatın müsaade edeceği yerdeğiştirme

\section{SONUÇLAR (CONCLUSIONS)}

Yeraltı maden kuyuları yeraltı maden ocakları için vazgeçilmez bir unsurdur. Maden kuyularının ilk yatırımları ve işletme maliyetleri oldukça yüksektir. Bu maliyet içerisinde en büyük payı ise kuyu duraylılığını sağlayacak tahkimat almaktadır. Bu çalışmada, $9 \mathrm{~m}$ çaplı ve $900 \mathrm{~m}$ derinliğe ulaşan düşey bir kuyunun beton tahkimat kalınlıkları, iki boyutlu sayısal analizler ile belirlenmiştir. Parametrik olarak dikkate alınan veriler; farklı derinlik (Z: 100-900m), tek eksenli basma dayanımı $\left(\sigma_{\mathrm{ci}}=50 \mathrm{MPa}\right)$, kaya kütle sınıflama sistemi (M-RMR: 10-100), kuyu kazısında patlatmaya dayalı çevre kayacın örselenme durumu (D: 0-0.5) dur. Parametrik bu çalışmada, toplam 100 senaryo model hazırlanmış ve analiz edilmiştir. Bütün senaryolar için $\mathrm{C} 20$ beton kalitesinde $\left(\sigma_{c c}=20 \mathrm{MPa}\right)$ optimum beton tahkimat kalınlıkları Phase2 yazılımı ile belirlenmiştir. Sayısal çözümlemeler yardımıyla sırasıyla, en büyük asal gerilme $\left(\sigma_{1}\right)$, toplam yerdeğiştirme $(\mathrm{U})$, kuyu çevre kayacında oluşan yenilen element sayısı, dayanım faktörü (SF) ve yenilme bölge kalınlığı $\left(h_{t}\right)$ davranışları belirlenmiştir. Dikkate alınan veri tabanı ile MRMR sınıflama sistemine bağlı beton tahkimat kalınlık değişimleri grafiksel formatta sunulmuştur. Ayrıca $9 \mathrm{~m}$ çaplı düşey kuyular için gerekli beton tahkimat tasarımında kullanılabilecek dört farklı grafikten oluşan bir bütünleyici abak tasarlanmıştır. Sonuç olarak bu çalışmada dikkate alınan 100 farklı senaryo için 10 abak hazırlanmıştır ancak bu makalede hepsi verilmemiştir. M-RMR kaya kütle sınıflama değerinin bilinmesi durumunda; geliştirilen ilgili abaktan kuyu çevre kayacında oluşan yenilme bölge kalınlığı $\left(h_{t}\right)$, beton tahkimat kalınlığı $\left(t_{c}\right)$ ve kuyu cidarında oluşacak yerdeğiştirme miktarı (U) belirlenebilmektedir. Bu çalışma ile önerilen beton tahkimat kalınlıkları ( $t_{c}$ ) optimum değerler olup uygulayan mühendisler, önerilen tahkimat beton kalınlıklarına eşit yada daha büyük 
değerler seçmelidirler. Son olarak, bu çalı̧̧madan elde edilen sonuçların tasarım girdi parametrelerinde ve çözümlemelerde yapılan bazı idealleştirmelerin göz önünde bulundurulduğu koşullarda geçerli olacağı da göz ardı edilmemelidir.

\section{TEŞEKKÜR (ACKNOWLEDGEMENT)}

Yazarlar, bu makalenin değerlendirmesinde eleştirileri ile katkı koyan hakemlere teşekkürü bir borç bilir.

\section{KAYNAKLAR (REFERENCES)}

Barton, N. R., Lien, R., Lunde, I., 1974, “Engineering Classification of Rock Masses for the Design of Tunnel Supports", Rock Mechanics, Vol.6(4), pp.189-239.

Bieniawski, Z. T., 1989, Engineering Rock Mass Classifications: A Complete Manual for Engineers and Geologists in Mining, Civil, and Petroleum Engineering, John Wiley \& Sons.

Bieniawski, Z.T., 1973, “Engineering Clasification of Jointed Rock Masses", Civil Engineer in South Africa, Vol. 15 (12), pp.335-343.

Carranza-Torres, C., Fairhurst, C., 2000, "The Elasto-Plastic Response of Underground Excavations in Rock Masses that Satisfy the Hoek-Brown Failure Criterion", International Journal of Rock Mechanics and Mining Sciences, Vol. 36(6), pp. 777-809.

Geniş, M., Acun, D., 2015, “Kuyu Duraylılığının Analitik ve Sayısal Yöntemler ile Karşılaştırmalı Bir İncelemesi", Çukurova Ün. Müh. Mimar. Fak. Derg., Vol. 30 (2), pp. 201-215.

Geniş, M., Derin, Z., 2016, "Zonguldak-Üzülmez Tünellerinin Çevre Kaya Özelliklerinin Belirlenmesi ve Duraylılığının Değerlendirilmesi", Karaelmas Fen ve Müh. Derg., Vol. 6 (1), pp. 144-151.

Hoek, E., Kaiser, P. K., Barwden, W. F., 1995, Support of Underground Excavations in Hard Rock, Belkema, Netherlands, 215p.

Ozkan I., 1989, Determination of Classification Parameters for Weak and Stratified Rocks Based on RMR and QSystems, MSc Thesis, 156p., METU, Ankara, Turkey.

Ozkan, I., 1995, "Modified Rock Mass Rating (M-RMR) System and Roof Behavior Model", Pht Thesis, 370p., METU, Ankara, Turkey.

Ozkan, I., Unal, E., 1996, "A Critical Review on Rock Mass Classification Systems", 3th Turkish Rock Mechanics Symposium, Ankara, Turkey, pp.181-193 (in Turkish).

Ozkan. I., Unal, E., 2012, Kaya Kütle Sinıflama Sistemleri ve M-RMR Sinflama Sisteminin Yeri, Gelişme Raporu, Selçuk Üniversitesi, Konya, 85s. (yayınlanmamış)

Rocscience, 2002, Phase2, Toronto, Canada, http://www.rocscience.com/

Rocscience, 2002, RocLab, Toronto, Canada, http://www.rocscience.com/

Saltoğlu, S., 1976, Madenlerde Hazırlık ve Kazı İşleri. İstanbul Teknik Üniversite matbaası, Gümüşsuyu, İTÜ, İstanbul, Türkiye, 336p.

Ulusay, R., Ozkan, I., Unal, E., 1992, Characterization of Weak, Stratified and Claybearing Rock Masses For Engineering Applications", Proceedings of the Fractured and Jointed Rock Masses Conference, Lake Tahoe, California, L.R. Mayer, N.G.W. Cook, R.E. Goodman and C.F. Trans (eds), 3-5 June 1992.

Unal, E., 1996, Modified Rock Mass Classification: M-RMR System, Milestone in Rock Engineering, The Bieniawski Jubilee Collection, Balkema, Rotterdam.

Unal, E., I. Ozkan, 1990, “Determination of Classification Parameters for Clay-bearing and Stratified Rock Mass", Proceedings of the 9th International Conference on Ground Control in Mining, Morgantown, USA, 4-6 June, 1990, pp. 250-259.

Unal, E., Ozkan, I., 1988, Zayıf-Tabakalı-Anizotropik-Kil İçerikli Kaya Kütleleri İçin Kaya Kütle Karakteristiği, Sivas I. Mühendislik Sempozyumu, Sivas.

Unal, E., Ozkan, I., Ulusay, R., 1992, "Characterization of Weak, Stratified and Claybearing Rock Masses", ISRM Symposium: EUROCK'92 Rock Characterization, Chester, UK, ed. J.A. Hudson, British Geotechnical Society, London, 14-17 September 1992, pp.330-335. 